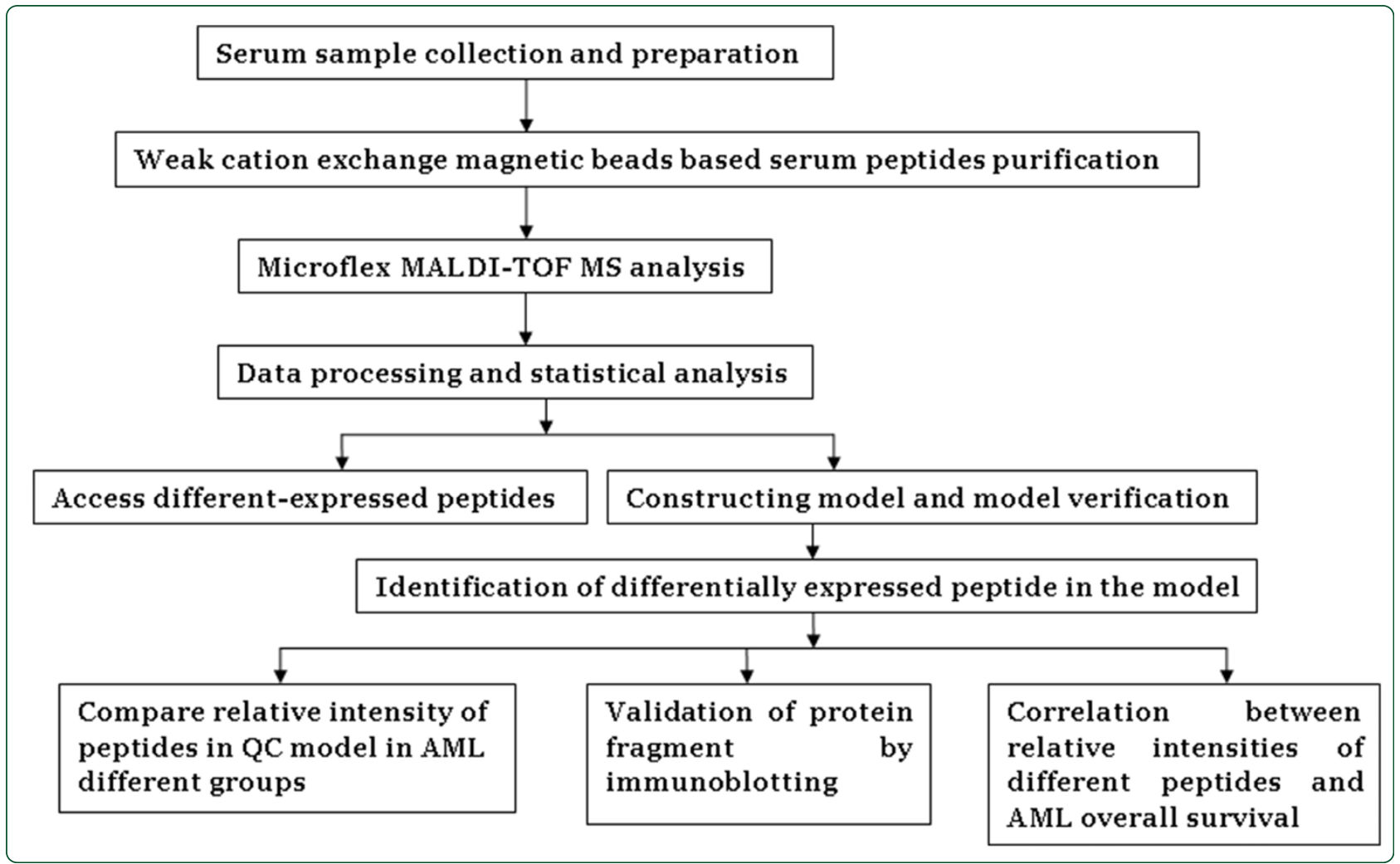

\title{
Potential biomarkers for adult acute myeloid leukemia minimal residual disease assessment searched by serum peptidome profiling
}

Bai et al. 


\title{
Potential biomarkers for adult acute myeloid leukemia minimal residual disease assessment searched by serum peptidome profiling
}

\author{
Ju Bai ${ }^{1}$, Aili He ${ }^{1 *}$, Wanggang Zhang ${ }^{1 *}$, Chen Huang ${ }^{2}$, Juan Yang ${ }^{2}$, Yun Yang ${ }^{1}$, Jianli Wang ${ }^{1}$ and Yang Zhang ${ }^{1}$
}

\begin{abstract}
Background: Post treatment minimal residual disease (MRD) determination contributes to impending relapse prediction, chemotherapy response and clinical outcomes assessment, guiding clinicians to develop reasonable and effective individual chemotherapy options after induction/consolidation. This study was to identify serum candidate peptides for monitoring adult acute myeloid leukemia (AML) MRD.

Results: 47 statistically different expressed peptide peaks were obtained in the molecular weight range of 700-10000 Da. Quick classifier (QC) model had optimal distinction efficiency, in the training set with a sensitivity of $90 \%$ and a specificity of $93.33 \%$. Peptides were identified as ubiquitin-like modifier activating enzyme 1(UBA1), isoform 1 of fibrinogen alpha chain precursor and platelet factor 4(PF4). The peptide up-regulated in newly diagnosed AML patients were decreased to the normal level after CR. When refractory \& relapsed, relative intensity was elevated again. Results were contrary to down-regulated peptide peaks. Western blot demonstrated that levels of the UBA1 protein did not differ between the leukemia and normal cells. Levels of isoform 1 of fibrinogen alpha chain precursor protein and PF4 protein were both decreased in leukemia cells comparing with normal cells. The serum levels of the PF4 in the newly diagnosed AML patients and healthy controls were significantly different. Further correlation analysis did not indicate the correlated relation between platelet counts and PF4 content, the correlation coefficient was 0.097 . Kaplan-Meier analyses of overall survival showed that relative intensity of peptides was correlated with patient's clinical outcome.
\end{abstract}

Conclusions: We speculate the peptides can be used as potential markers for monitoring minimal residual disease and clinical outcome assessment.

Keywords: Weak cation exchange magnetic beads, MALDI-TOF-MS, Serum peptidome profiling, Adult acute myeloid leukemia, Minimal residual disease

\section{Background}

Acute myeloid leukemia(AML), a clonal expansion, accumulation and infiltration of myeloid hematopoietic blasts, is a highly heterogeneous hematological malignancy comprising many entities for which distinct treatment strategies are pursued [1]. Although M3 is a success story in AML oncology (cure rate more than 90\%), clinical effects in non-M3 AMLs lag behind those in M3 [2]. The poor long-term disease-free survival rates

\footnotetext{
* Correspondence: heaili@mail.xjtu.edu.cn; zhangwanggang2003@yahoo.com 'Department of Hematology, Second Affiliated Hospital, Medical School of Xi'an Jiaotong University, 157 Xiwu Road, Xincheng District, Xi'an, Shaanxi 710004, PR China

Full list of author information is available at the end of the article
}

of adult AML is mainly due to therapy-related mortality, failure of induction chemotherapy and early relapse [3]. Risk stratification adapted therapies based on prognostic factors will help to improve the clinical outcomes. But indeed, patients with favorable karyotype accounts for approximately $40 \%$ to $50 \%$ of low-risk AML will eventually experience a relapse. For patients falling into the intermediate risk karyotype ( 60\%), post remission strategies-planning lacks accepted criteria. Lots of studies have shown that minimal residual disease (MRD) positive patients are at high risk of relapse, while MRDnegative cases manifest lower risk of relapse in patients with acute promyelocytic leukemia and acute lymphoblastic leukemia clinically. Nowadays, post treatment

\section{Biomed Central}


MRD determination appears to be appropriate in extrapolating the risk of relapse, assessing chemotherapy response and planning individual chemotherapy regimen after induction/consolidation [4].

Leukemia relapse is mainly due to the presence of MRD. Leukemia MRD level monitoring contributes to anticipation of impending relapse and assessment of clinical outcomes, guiding clinicians to develop reasonable and effective treatment options so that patients can avoid unnecessary chemical drug toxicity. Currently, MRD monitoring is mainly through detecting remaining leukemia cells in bone marrow by multi-parameter flow cytometry phenotype analysis and real-time quantitative polymerase chain reaction (RTQ-PCR). But multiparameter flow cytometry phenotype analysis can't be carried out in lots of hospitals and lack standardized procedure, the number of fusion genes known in acute leukemia is limited and RTQ-PCR assays shows poverty in standardized cut-offs. Moreover, bone marrow aspiration is invasive and increases the patient's pain. Because most non-M3-AML patients lack specific fusion genes, so after every stage of chemotherapy, the response is mainly judged by whether the leukemia cells in the bone marrow are less than $5 \%$. As bone marrow aspiration site is single, leukemia cells are not typical after multiple chemotherapy, bone marrow smears need long-term film-reading experience and skilled clinical hematological workers to read. Serum is easily accessible, can record different physiological or pathological conditions at any time and readily accepted by patients, therefore, it becomes one of the best sources for biomarkers researching.

Serum peptide profile method is known as "The new health fingerprint library" technology and has been accepted worldwide. It is through analysing and comparing differences in the expression of serum peptides between target population and normal healthy population, to find multiple different-expressed serum peptides, to map out disease-specific serum peptide spectrum, to diagnose disease, to clarify the possible pathogenesis and resistance mechanism, and to determine prognosis [5].

Proteomics technology has been applied to study hematological malignancies in some previous researches. The traditional two-dimensional gel electrophoresis (2-DE)-based separation technology combined matrix assisted laser desorption ionization time of flight mass spectrometry (MALDI-TOF-MS) or Protein chip-surface enhanced laser desorption ionization time of flight mass spectrometry (SELDI-TOF-MS) technology were mainly used to study cell lines and/or bone marrow cells. The aim of those researches was to find early diagnostic markers, to predict the prognosis of hematologic malignancies, to explore the molecular mechanisms of anticancer drugs and to develop molecular targeted drugs based on theses biomarkers. Although the cultured cell lines have high purity and are easy to operate, but they are difficult to reflect the real situation of the disease. Due to the complex composition and high cell heterogeneity of bone marrow, researchers analyzed serum samples of different hematologic malignancies in recent years using 2-DE combined with MALDI-TOF-MS or Protein chip-SELDI-TOF-MS, for instance, Albitar [6], Zou [7] and Mohamedali [8] had established the diagnostic model of leukemia with high sensitivity and specificity, and further identified the leukemia-related markers, such as Rho-GDP dissociation inhibitor autoantibodies, alpha enolase, aldolase enzyme $\mathrm{A}$ and so on [9]. These markers play an important role in the early diagnosis, differential diagnosis and pathogenesis of acute leukemia.

In order to facilitate peptide identification, we replaced solid chip with beads for sample purification and enrichment, and we employed MALDI-TOF MS technology for mass spectra acquisition, and highly sophisticated data mining algorithms for inspection and comparison of data sets as well as for the discovery of complex biomarker pattern models [10]. The ClinProt technology has lots of advantages, such as a large separation capacity [11], enriched samples easy to elute for further identification [12], simple and quick operation, high-throughput, software parallelization analysis, differentially expressed forms, etc. [13]. ClinProt technology-based serum peptide spectra was first used in ovarian cancer research [14], then widely used for early diagnosis, pathogenesis interpretation, therapeutic targets selection in melanoma [15], colorectal [16], breast cancer and other solid tumors $[17,18]$. Previously, our group applied ClinProt system to compare and analysis the difference between newly diagnosed multiple myeloma (MM) and healthy controls in serum peptide spectrum, and we established a diagnostic model with high sensitivity and specificity based on Supervised Neural Network Algorithm (SNN) [19].

In view of this, this study used weak cation exchange magnetic beads (MB-WCX) combined with MALDITOF-MS to analyze serum peptide profiling of adult AML patients in different disease groups (newly diagnosed group, complete remission (CR) group, refractory \& relapsed group) and healthy control group, and then used high performance liquid chromatography electro spray ionization tandem mass spectrometry (HPLC-ESIMS/MS) to identify candidate peptides. These protein fragments were validated by immunoblotting. Three peptides are identified as ubiquitin-like modifier activating enzyme 1(UBA1), isoform 1 of Fibrinogen alpha chain precursor and platelet factor 4(PF4). They are correlated with AML clinical outcome and would be appropriately adapted for predicting AML relapse, monitoring MRD and predicting prognosis in clinical practice. 
Table 1 Reproducibility of mass spectra processed by ClinProt system

\begin{tabular}{cccccc}
\hline \multirow{2}{*}{$\mathbf{m} / \mathbf{z}$} & \multicolumn{2}{c}{ Within-run arrays } & & \multicolumn{2}{c}{ Between-run arrays } \\
\cline { 2 - 3 } \cline { 6 - 6 } & MRI\% & CV\% & & MRI\% & CV\% \\
\hline 973.15 & 4.2 & 14.2 & & 4.1 & 14.3 \\
1866.09 & 8.8 & 9.8 & & 8.6 & 10.5 \\
2661.27 & 2.1 & 8.3 & & 2.2 & 8.6 \\
3443.92 & 4.9 & 12 & & 5.2 & 12.4 \\
4089.70 & 3.4 & 23 & & 3.2 & 23.4 \\
4208.76 & 13.1 & 16.5 & & 13.6 & 17.2 \\
5902.57 & 10.1 & 14.6 & & 10.8 & 15.3 \\
6628.07 & 7.2 & 18.1 & 6.9 & 20.9 \\
7762.87 & 6.1 & 24.8 & 5.8 & 27.3 \\
9288.31 & 1.7 & 5.6 & 1.6 & 6.4 \\
\hline
\end{tabular}

$\mathrm{m} / \mathrm{z}$ mass to charge ratio, $M R I$ mass relative intensity, $C V$ coefficient of variation.

\section{Results}

Repeatability of ClinProt system based peptidome detection

ClinProt system repeatability was evaluated based on the serum peptide fingerprints of the same serum sample processed in triplicate (Additional file 1: Figure S1). The two figures show that the peptide peaks are consistent in the three detections, indicating that ClinProt system has good repeatability.

Moreover, coefficient of variation $(\mathrm{CV})$ value was used to evaluate repeatability and stability of serum peptide fingerprint in international. It is required that CV should be less than $30 \%$ [20]. In this study, the CV of the relative intensity of peptides in MALDI-TOF-MS peptide spectra was calculated to evaluate repeatability of the serum peptide fingerprints method (Table 1). The average CV value of within-run arrays was $14.7 \%$ $(5.6 \%-24.8 \%)$ and that of between-run arrays was $15.6 \%$ $(6.4 \%-27.3 \%)$.

\section{Analysis of newly diagnosed AML and healthy control serum peptide fingerprint by ClinProt system}

To screen serum peptides of interest for AML, we made the comparison in serum peptide fingerprints between AML patients and healthy controls, showing that peak number and intensity of newly diagnosed AML patients' serum peptide fingerprint were completely different from healthy controls' (Figure 1), these significant different mass peaks were likely to be the AML potential characteristic peptides.

Comparative analysis of peptide fingerprint revealed that there were a total of 47 different expressed peptide peaks with statistical significance in the MW range of 700-10000 Da $(\mathrm{p}<0.05)$. Among which, the expressions of 12 peptides were up-regulated and that of 35 peptides were down-regulated in AML newly diagnosed group (Table 2).

\section{Establishment QC diagnostic model and blind verification} Genetic algorithm (GA), SNN and QC were applied to establish diagnostic model for distinguishing newly diagnosed AML from healthy control. Among them, QC model composed of three peptides had optimal distinction efficiency (90\% sensitivity and $93.33 \%$ specificity) in the training set.

In the QC model, the peptide with MW of 3216.57 Da was up-regulated in AML newly diagnosed group (Figure 2A), peptides with MW of $4089.7 \mathrm{Da}$ and $7762.87 \mathrm{Da}$ were both down-regulated (Figure 2B,C).

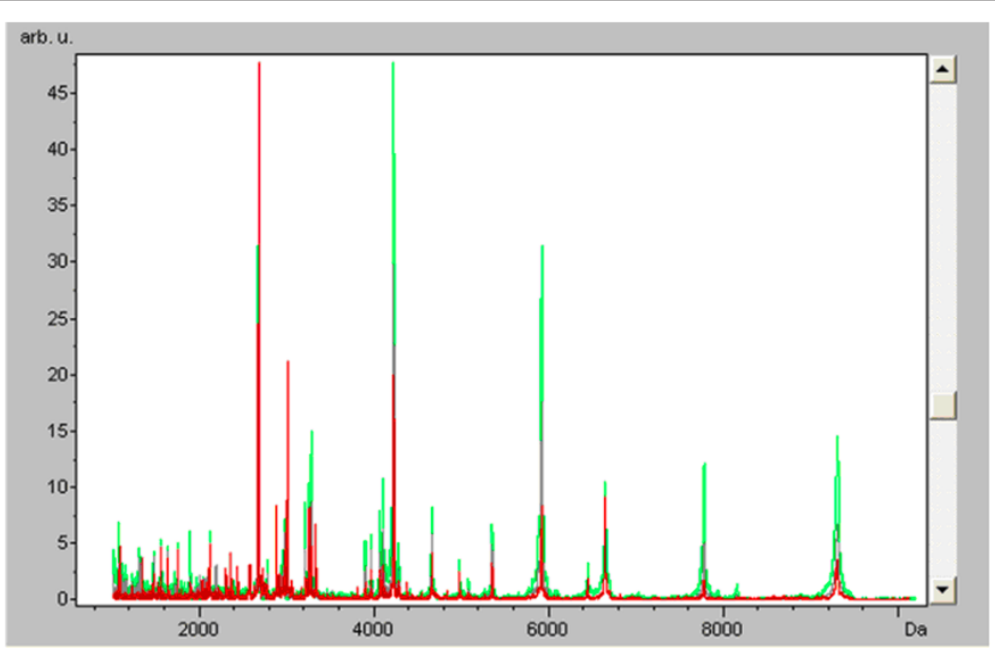

Figure 1 Serum peptide fingerprint and cluster analysis of newly diagnosed AML and healthy control. Comparison of serum peptide fingerprints between AML patients and healthy controls showed that peak number and intensity of the two groups were completely different. (Red: AML newly diagnosed group Green: Healthy control group). 
Table 2 Different expression peptides between newly diagnosed AML group and healthy control group

\begin{tabular}{|c|c|c|c|c|c|c|c|c|}
\hline Index & Mass & Dave & $P$ value & Ave1 & Ave2 & StdDev1 & StdDev2 & Expression change \\
\hline 48 & 4208.76 & 29.66 & 0.00000192 & 10.64 & 40.31 & 10.37 & 13.98 & $\downarrow$ \\
\hline 12 & 1866.09 & 18.67 & 0.000489 & 22.08 & 3.41 & 25.9 & 1.6 & $\uparrow$ \\
\hline 60 & 5902.57 & 16.49 & 0.0000421 & 10.02 & 26.51 & 9.35 & 11.59 & $\downarrow$ \\
\hline 64 & 6628.07 & 9.4 & 0.00000388 & 13.85 & 4.45 & 7.71 & 3.24 & $\uparrow$ \\
\hline 69 & 9286.53 & 7.84 & 0.00000192 & 2.34 & 10.19 & 2.03 & 4.38 & $\downarrow$ \\
\hline 34 & 3262.18 & 7.49 & 0.0000723 & 5.78 & 13.27 & 7.05 & 6.55 & $\downarrow$ \\
\hline 42 & 4089.7 & 7.39 & 0.00000108 & 2.69 & 10.08 & 1.39 & 4.03 & $\downarrow$ \\
\hline 66 & 7762.87 & 6.42 & 0.00000108 & 1.94 & 8.36 & 1.25 & 3.35 & $\downarrow$ \\
\hline 4 & 1282.99 & 5.83 & 0.00000203 & 2.57 & 8.41 & 0.63 & 6.16 & $\downarrow$ \\
\hline 52 & 4643.21 & 5.66 & 0.0000168 & 2.37 & 8.03 & 1.75 & 4.4 & $\downarrow$ \\
\hline 5 & 1299.56 & 5.53 & 0.00000108 & 2.33 & 7.87 & 0.57 & 5.26 & $\downarrow$ \\
\hline 30 & 2990.42 & 5.3 & 0.00000146 & 6.88 & 1.57 & 5.08 & 0.68 & $\uparrow$ \\
\hline 36 & 3315.58 & 5.05 & 0.00000203 & 7.05 & 2 & 3.74 & 1.15 & $\uparrow$ \\
\hline 31 & 3191.17 & 4.61 & 0.00000625 & 2.7 & 7.31 & 1.63 & 3.51 & $\downarrow$ \\
\hline 19 & 2168.67 & 4.45 & 0.0000573 & 2.04 & 6.5 & 0.71 & 5.51 & $\downarrow$ \\
\hline 39 & 3950.86 & 4.17 & 0.00000203 & 2.56 & 6.73 & 1.27 & 2.76 & $\downarrow$ \\
\hline 20 & 2184.85 & 4.05 & 0.0116 & 2.54 & 6.59 & 1.06 & 5.72 & $\downarrow$ \\
\hline 29 & 2952.24 & 4.03 & 0.00616 & 4.57 & 8.6 & 3.14 & 5.22 & $\downarrow$ \\
\hline 47 & 4192.99 & 4.01 & 0.00000515 & 2.46 & 6.48 & 1.31 & 2.79 & $\downarrow$ \\
\hline 18 & 2105.44 & 3.74 & 0.0000127 & 3.05 & 6.79 & 1.55 & 2.99 & $\downarrow$ \\
\hline 56 & 5335.01 & 3.21 & 0.000605 & 3.42 & 6.62 & 2.95 & 3.29 & $\downarrow$ \\
\hline 40 & 4052.81 & 3.07 & 0.000206 & 3.13 & 6.21 & 2.83 & 2.37 & $\downarrow$ \\
\hline 62 & 6430.27 & 3.02 & 0.0000335 & 4.67 & 1.66 & 3.69 & 1.13 & $\uparrow$ \\
\hline 2 & 1100.81 & 2.86 & 0.000259 & 2.62 & 5.48 & 1.01 & 3.23 & $\downarrow$ \\
\hline 13 & 1982.13 & 2.55 & 0.000137 & 2.21 & 4.75 & 0.63 & 3.1 & $\downarrow$ \\
\hline 37 & 3882.23 & 2.53 & 0.000257 & 2.19 & 4.73 & 1.01 & 2.17 & $\downarrow$ \\
\hline 16 & 2062.28 & 2.38 & 0.0000723 & 1.69 & 4.07 & 0.45 & 2.68 & $\downarrow$ \\
\hline 25 & 2768.83 & 2.28 & 0.00000108 & 1.81 & 4.09 & 0.51 & 1.52 & $\downarrow$ \\
\hline 15 & 2037.71 & 2.26 & 0.0075 & 1.84 & 4.1 & 0.35 & 3.12 & $\downarrow$ \\
\hline 17 & 2069.96 & 2.19 & 0.000749 & 2.02 & 4.21 & 0.46 & 2.65 & $\downarrow$ \\
\hline 59 & 5864.9 & 2.18 & 0.000247 & 2.47 & 4.65 & 1.15 & 1.85 & $\downarrow$ \\
\hline 53 & 4818.02 & 2.17 & $<0.000001$ & 2.68 & 0.51 & 3.32 & 0.18 & $\uparrow$ \\
\hline 50 & 4265.7 & 1.88 & 0.000749 & 2.46 & 4.34 & 1.07 & 1.85 & $\downarrow$ \\
\hline 14 & 2021.95 & 1.8 & 0.00326 & 4.64 & 2.84 & 2.37 & 3.02 & $\uparrow$ \\
\hline 28 & 2932 & 1.59 & 0.000605 & 2.63 & 4.22 & 0.81 & 1.56 & $\downarrow$ \\
\hline 46 & 4167.87 & 1.56 & 0.0000437 & 1.69 & 3.25 & 0.84 & 1.02 & $\downarrow$ \\
\hline 41 & 4071.18 & 1.39 & 0.000029 & 1.53 & 2.92 & 0.38 & 0.94 & $\downarrow$ \\
\hline 33 & 3240.42 & 1.23 & 0.00958 & 7.47 & 8.7 & 9.41 & 3.17 & $\downarrow$ \\
\hline 65 & 6662.81 & 1.13 & 0.0000187 & 2.28 & 1.15 & 0.93 & 0.56 & $\uparrow$ \\
\hline 61 & 5957.41 & 1.08 & 0.0000299 & 1.06 & 2.14 & 0.26 & 0.95 & $\downarrow$ \\
\hline 32 & 3216.57 & 1.04 & 0.00357 & 2.87 & 1.83 & 1.45 & 0.53 & $\uparrow$ \\
\hline 63 & 6526.9 & 0.79 & 0.00000268 & 1.37 & 0.58 & 0.52 & 0.25 & $\uparrow$ \\
\hline 44 & 4121.48 & 0.78 & 0.000259 & 1.62 & 2.4 & 0.38 & 0.71 & $\downarrow$ \\
\hline 38 & 3933.89 & 0.77 & 0.0000406 & 1.42 & 2.19 & 0.38 & 0.65 & $\downarrow$ \\
\hline
\end{tabular}


Table 2 Different expression peptides between newly diagnosed AML group and healthy control group (Continued)

\begin{tabular}{llllllllll}
\hline 21 & 2561.11 & 0.69 & 0.0309 & 2.59 & 1.9 & 1.27 & 0.63 & $\uparrow$ \\
43 & 4108.19 & 0.66 & 0.000357 & 1.37 & 2.03 & 0.42 & 0.56 & $\downarrow$ \\
45 & 4152.3 & 0.18 & 0.0206 & 2.41 & 2.22 & 2.65 & 0.68 & $\uparrow$ \\
\hline
\end{tabular}

Index peptide peak index, Mass mass to charge ratio value, Dave differences of average peak intensity between newly diagnosed AML group and healthy control group, $P$ value $\mathrm{p}$ value of t-test, Ave 1 average peak intensity of newly diagnosed AML group, Ave2 average peak intensity of healthy control group, StdDev1 standard deviation of the peak intensity average of newly diagnosed AML group, StdDev2 standard deviation of the peak intensity average of healthy control group.

Blind test verified that this model correctly identified 40 cases out of total 42 AML cases and 39 healthy cases from 42 healthy controls.

\section{Peptide identification}

The three peptides in QC model were purified and identified by HPLC-ESI-MS/MS. Data analysis software Bioworks Browser 3.3.1 SP1 was performed for Sequest ${ }^{\mathrm{TM}}$ searching. Positive protein identification was accepted for a peptide with Xcorr of greater than or equal to 3.50 for triply charged ions and 2.5 for doubly charged ions, and all with $\Delta \mathrm{Cn} \geq 0.1$, peptide probability $\leq 1 \mathrm{e}-3$. The three peptides were identified as ubiquitin-like modifier activating enzyme 1(UBA1), isoform 1 of Fibrinogen alpha chain precursor and platelet factor 4(PF4), respectively (Table 3). Figures 3, 4 and 5 show the identification of specific $b$ and $y$ ions for sequences of the three peptides.

\section{Determination of serum PF4 by enzyme linked immunosorbent assay}

We detected serum PF4 content by enzyme linked immunosorbent assay (ELISA) in 40 cases of newly diagnosed AML and 40 healthy controls. Compared with healthy control group, PF4 content in newly diagnosed AML group was decreased (newly diagnosed AML vs. control, $0.8012 \pm 0.1876$ vs. $3.2604 \pm$ $1.0454, p=1.8638 \mathrm{E}-6)$. To eliminate the influence of platelet count on serum PF4 content, correlation analysis was further done between platelet count and PF4 content. Correlation coefficient was $0.213(\mathrm{p}=0.186)$, and no correlation was found between them (Figure 6). It follows that reduction of serum PF4 content in newly diagnosed AML is not due to thrombocytopenia.

\section{Validation of protein fragment by immunoblotting}

Next, we sought to determine the level of UBA1, isoform 1 of fibrinogen alpha chain precursor and PF4 protein in AML and control samples by western blot analysis. Levels of the UBA1 protein did not differ among the leukemia and normal cells by immunoblotting $(\mathrm{p}=0.849$, Figure 7A,B). Isoform 1 of fibrinogen alpha chain precursor and PF4 immunoreactive bands show that weak or no bands are seen in newly diagnosed and refractory \& relapsed AML cases (Figure 7A). Quantification of bands from western blot analysis showed decreased level of the two proteins in AML samples, relative to age-matched CR AML and healthy control samples significantly ( $\mathrm{p}=$ 0.00368, $\mathrm{p}=0.00067$, Figure 7C,D).

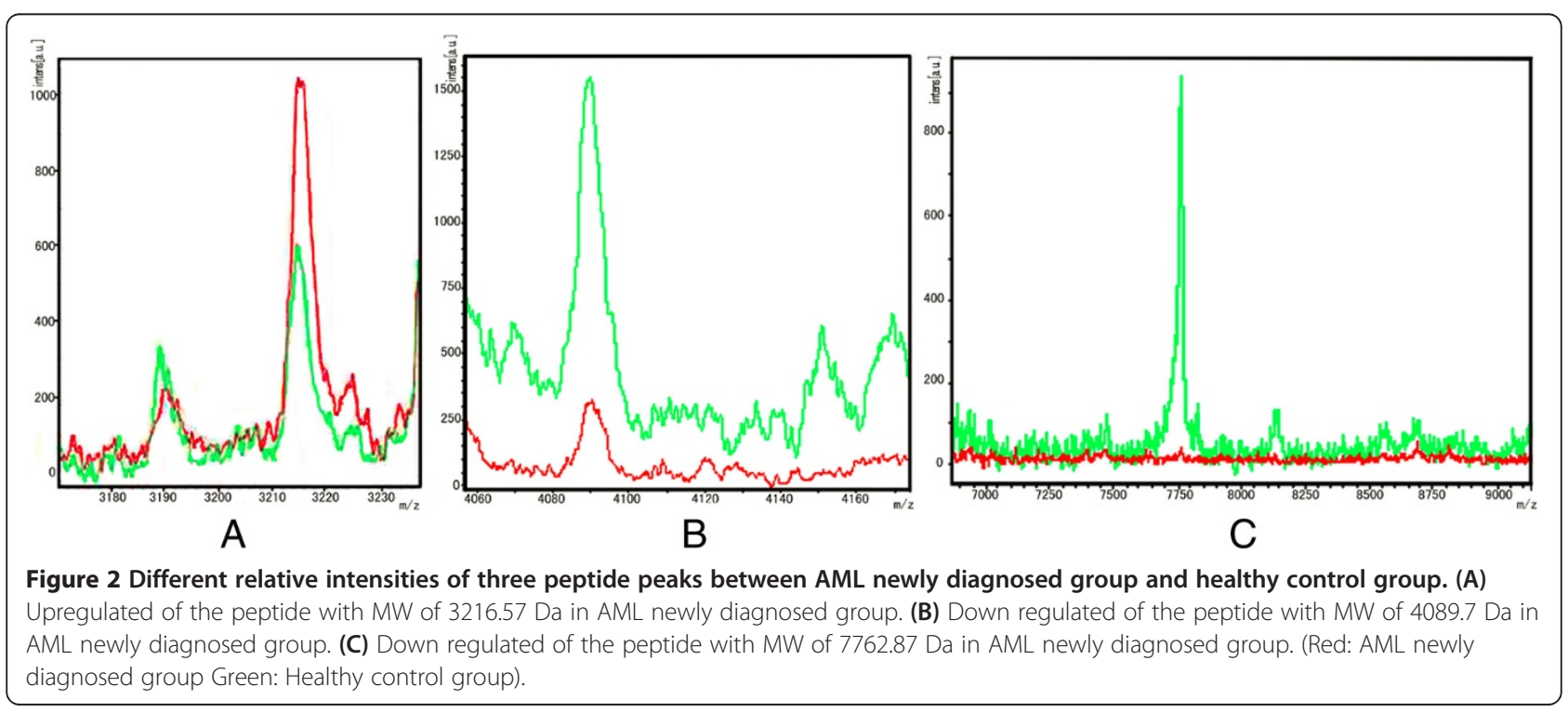


Table 3 Peptides sequencing and identification results

\begin{tabular}{cccc}
\hline $\begin{array}{l}\text { Molecular } \\
\text { weight }\end{array}$ & Amino acid sequence & $\begin{array}{c}\text { International } \\
\text { protein index }\end{array}$ & Peptide name \\
\hline $3216.57 \mathrm{Da}$ & HGFESGDFVSFSEVQGMVELNGNQPMEIK & IPI00641319 & $\begin{array}{c}\text { Ubiquitin-like modifier } \\
\text { activating enzyme } 1\end{array}$ \\
$4089.7 \mathrm{Da}$ & GDSTFESKSYKMADEAGSEADHEGTHSTKRGHAKSRPV & IPI00021885 & $\begin{array}{c}\text { Isoform } 1 \text { of Fibrinogen } \\
\text { alpha chain precursor }\end{array}$ \\
$7762.87 \mathrm{Da}$ & EAEEDGDLQCLCVKTSSQVRPRHITSLEVIKAGPHCPTAQLIATLKNGRKICLDLQAPLYKKIIKKLLES & IPI 00022446 & Platelet factor 4 \\
\hline
\end{tabular}

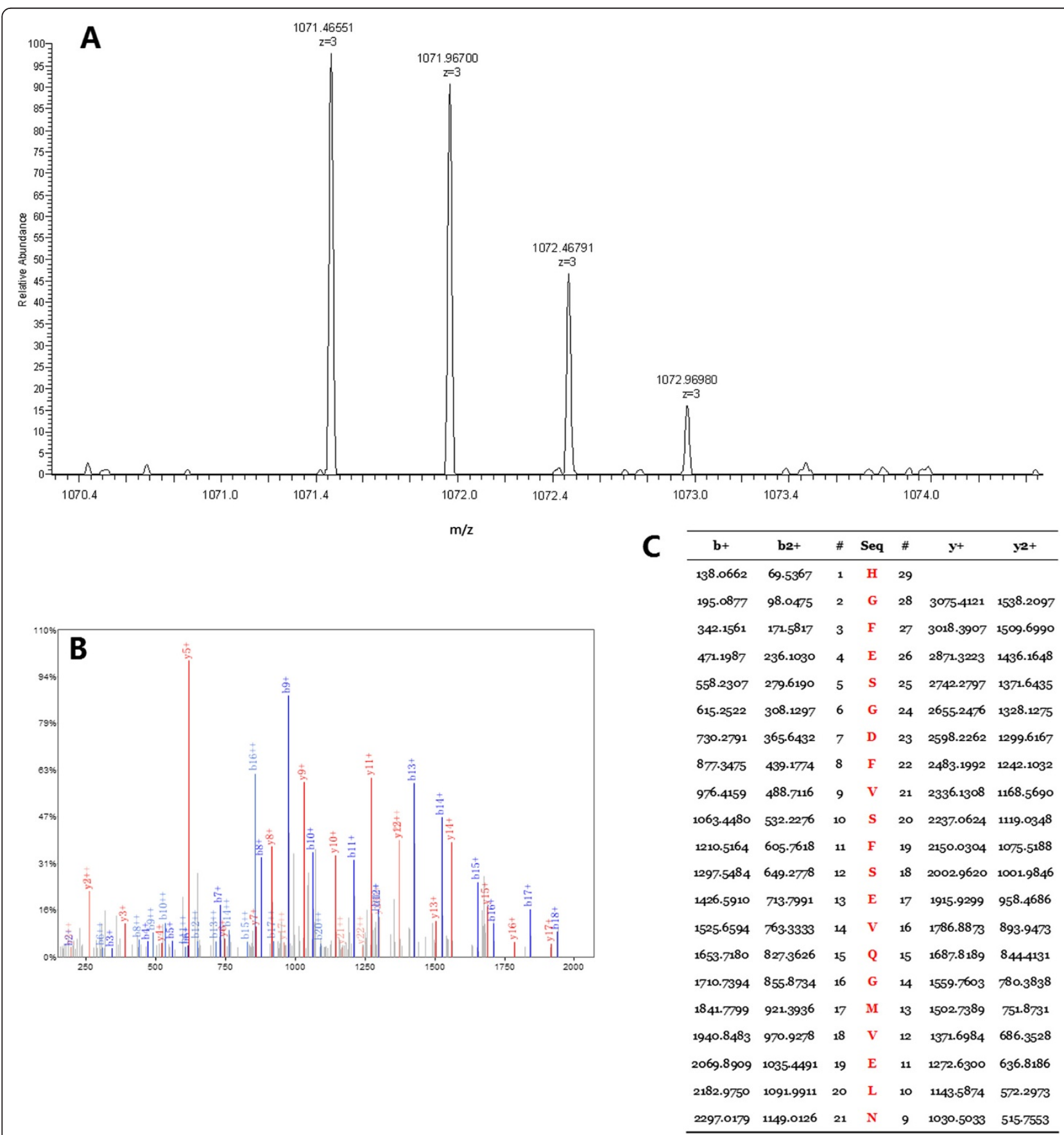

Figure 3 MS/MS map of peptide with MW of 3216.57 Da. (A) The enlarged picture of peptide with MW of 3216.57 Da. (B) The b and y ions spectra used to identify the peptide with MW of 3216.57 Da. (C) The sequence of the peptide with MW of 3216.57 Da. 


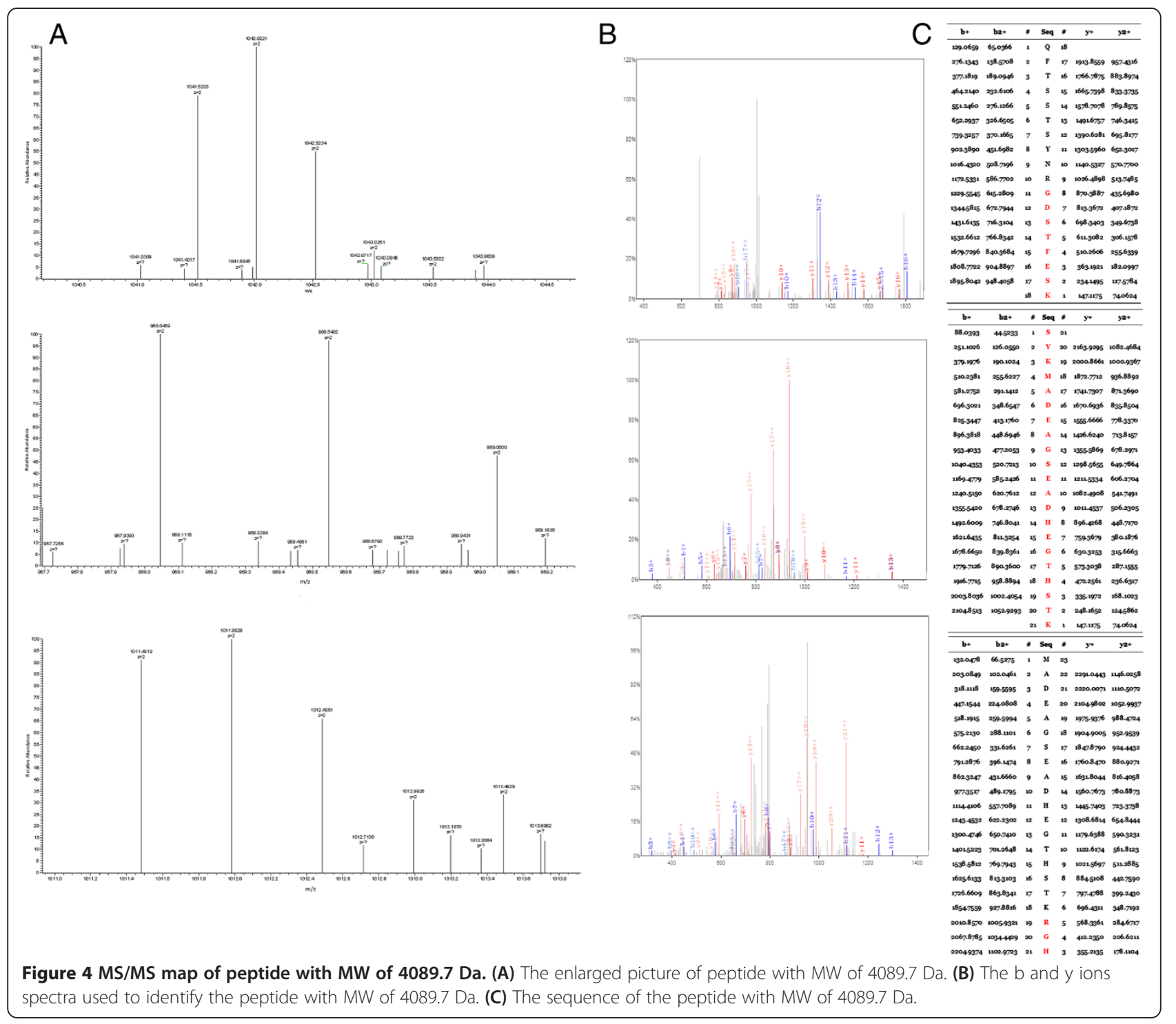

The relative intensity of three peptides in $Q C$ model in AML different groups

To explore the clinical significance of QC model, we compared the differences in the expression intensity of the three peptides (3216.57 Da, 4089.7 $\mathrm{Da}$ and $7762.87 \mathrm{Da})$ between AML newly diagnosed group, CR group, relapsed \& refractory group and healthy control group (Table 4).

The relative intensity of peptide with MW of 3216.57 Da was elevated in the AML newly diagnosed group and the relapsed \& refractory group, but no significant difference was observed between the two groups $(p=0.693)$. The relative intensity was reduced in the healthy control group and the CR group, no significant difference was observed between the two groups $(\mathrm{p}=0.83)$ either. But the relative intensity was significant elevated in newly diagnosed group and refractory
\& relapsed group, compared with healthy control group and CR group $(\mathrm{p}=0.00357, \mathrm{p}=0.0012, \mathrm{p}=0.0027$, $\mathrm{p}=0.0073)$.

The relative intensities of the peptides with MW of 4089.7 $\mathrm{Da}$ and $7762.87 \mathrm{Da}$ were both reduced in the AML newly diagnosed group and the refractory \& relapsed group, but no statistical difference was observed between the two groups $(\mathrm{p}=1.63, \mathrm{p}=0.53)$. The relative intensities were elevated in the healthy control group and the CR group, no significant differences were observed between the two groups $(p=1.92, p=0.83)$ either, but the relative intensities were significantly reduced in the newly diagnosed group and the refractory \& relapsed group, compared with healthy control group and CR group $(\mathrm{p}=0.00357, \mathrm{p}=0.0012, \mathrm{p}=0.0027$, $\mathrm{p}=0.0073, \mathrm{p}=0.00000108, \mathrm{p}=0.00000118, \mathrm{p}=0.00000001$, $\mathrm{p}=0.00000021$. 


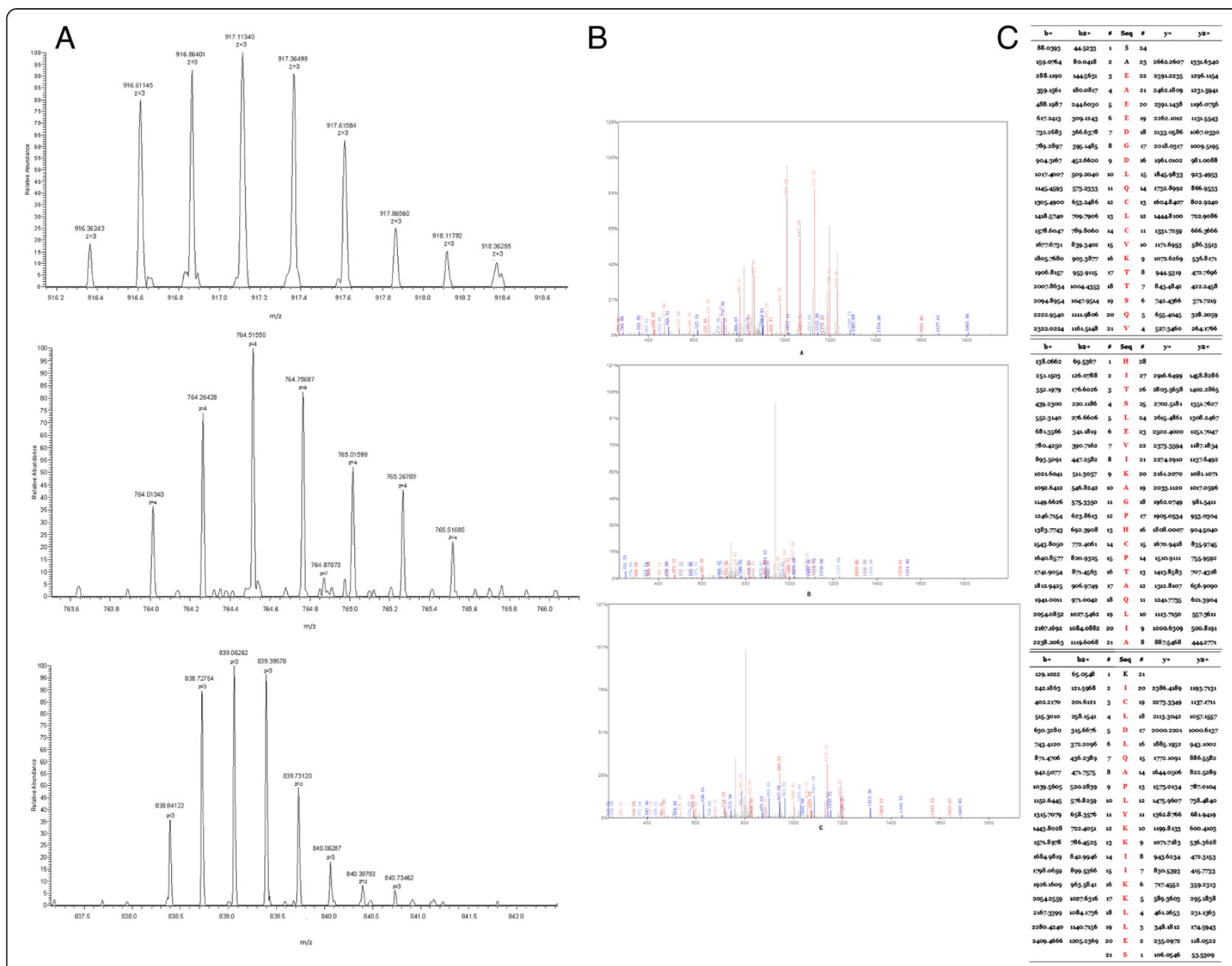

Figure 5 MS/MS map of peptide with MW of 7762.87 Da. (A) The enlarged picture of peptide with MW of 7762.87 Da. (B) The b and y ions spectra used to identify the peptide with MW of $7762.87 \mathrm{Da}$. (C) The sequence of the peptide with MW of $7762.87 \mathrm{Da}$.

\section{Impact of the relative intensity of three peptides on survival}

The median follow-up duration among 72 patients was 19 months (range 4-38 months). The patients were categorized into two groups according to the relative intensity of peptides ( $\geq$ mean versus $<$ mean). Kaplan-Meier analyses of overall survival (OS) showed that patients with higher relative intensity of ubiquitin-like modifier activating enzyme 1 ( $\geq$ mean relative intensity) had a significantly inferior outcome. Lower relative intensity of ubiquitin-like modifier activating enzyme $1(<$ mean relative intensity) was associated with an favorable OS $(19.9 \pm 7.0 \%$ versus $42.5 \pm 9.8 \%, \mathrm{P}=0.037$; Figure $8 \mathrm{~A})$. The OS rate was higher in patients with increased relative intensity ( $\geq$ mean relative intensity) of isoform 1 of fibrinogen alpha chain precursor and platelet factor 4 than in those with decreased relative intensity ( $<$ mean relative intensity) $(48.5 \pm 10.7 \%$ versus $19.2 \pm 7.2 \%, \mathrm{p}=0.015 ; 48.5 \pm 9.0 \%$ versus $21.7 \pm 8.5 \%, \mathrm{P}=0.031$, Figure $8 \mathrm{~B}$ and $\mathrm{C}$ ).

\section{Discussion}

AML is a highly heterogeneous disease with distinct manifestations and prognostic and therapeutic implications. Leukemia MRD level monitoring contributes to impending relapse anticipation and clinical outcomes assessment, further guide's clinicians to develop reasonable and effective treatment options so that patients can avoid unnecessary chemical drug toxicity.

Our QC model composed of three peptides achieved high sensitivity (90\%) and specificity (93.33\%) between newly diagnosed AML group and healthy controls. The peptides may be unique to AML and the AML specimen volume is up for augmentation for verification. The peptides could be purified to analyze their functions, so as to clear whether they are implicated in leukemogenesis.

Through document retrieval, there are only two workers applied ClinProt technology for studying AL patients serum peptide fingerprint to seek for the AL biomarkers. Elssner's group made a comparative analysis of 

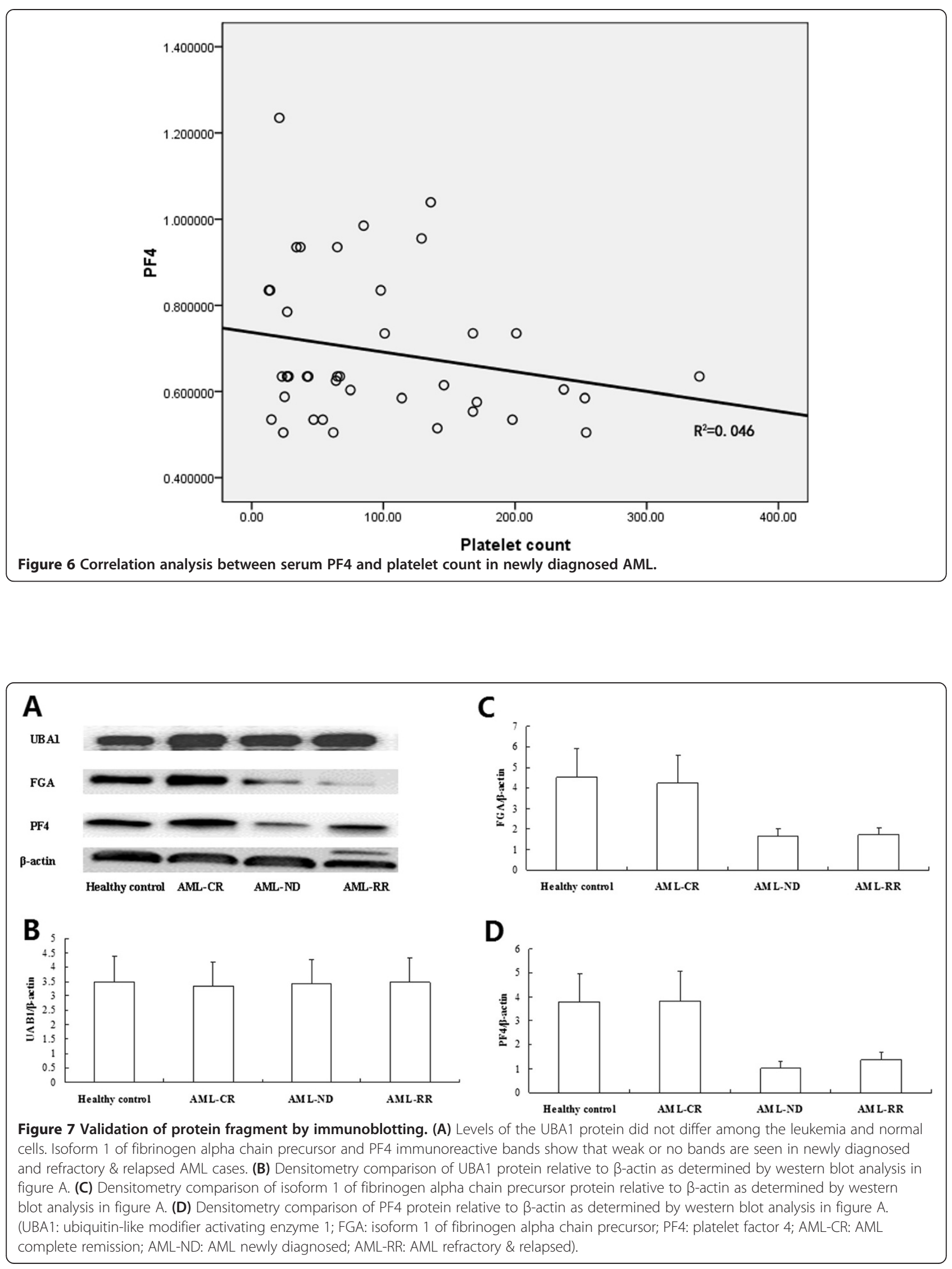
Table 4 Relative intensity of three peptides in AML different groups and healthy control group

\begin{tabular}{|c|c|c|c|c|c|c|c|c|}
\hline Mass & Ave1 \pm StdDev1 & Ave2 \pm StdDev2 & Ave $3 \pm$ StdDev3 & Ave $4 \pm$ StdDev4 & $\mathrm{n} 1$ & $\mathrm{n} 2$ & n3 & $\mathrm{n} 4$ \\
\hline 3216.57 & $2.87 \pm 1.45$ & $1.83 \pm 0.53$ & $1.76 \pm 0.48$ & $3.08 \pm 1.58$ & 72 & 72 & 37 & 30 \\
\hline 4089.7 & $2.69 \pm 1.39$ & $10.08 \pm 4.03$ & $11.63 \pm 4.51$ & $2.51 \pm 1.35$ & & & & \\
\hline 7762.87 & $1.94 \pm 1.25$ & $8.36 \pm 3.35$ & $8.62 \pm 3.55$ & $1.73 \pm 1.18$ & & & & \\
\hline
\end{tabular}

Mass mass to charge ratio value, Ave average peak intensity, StdDev standard deviation of the peak intensity, $n$ number of patients, 1 AML newly diagnosed group, 2 healthy control group, $3 \mathrm{AML} C R$ group, $4 \mathrm{AML}$ refractory \& relapsed group.

the serum peptide spectrum between childhood ALL and healthy controls and obtained an optimum discriminatory pattern proposed by ClinProTools after MB-HIC C8 enrichment. This model contained four relevant peaks: $2438 \mathrm{~m} / \mathrm{z}, 6458 \mathrm{~m} / \mathrm{z}, 7771 \mathrm{~m} / \mathrm{z}$ and $9421 \mathrm{~m} / \mathrm{z}$. They may be four potential biomarkers for childhood ALL [21]. Liang's group performed Copper-chelated magnetic bead fractionation/MALDI-TOF-MS analysis on sera from patients with newly diagnosed AML, CR after chemotherapy and healthy control, found that two peptides with $\mathrm{m} / \mathrm{z} 1778.05$ and 1865.13 were gradually decreased in their relative intensities with increase of remission degree, especially in molecular remission. With FT-ICR-MS detection, both peptides were identified as fragments of complement C3f, suggesting that the two peptides have the potential for monitoring of MRD [22].

The AML candidate peptides screened in our study are different from those in previous studies. The specific reasons are as follows: 1) Technically, we applied MBWCX based ClinProt system. Some researchers made a comparison among beads with hydrophobic interaction chromatography C8 (MB-HIC-C8), MB-WCX and immobilized metal-ion affinity chromatography (MBIMAC-Cu), indicating that the serum samples purified by MB-WCX group provided the best proteomic pattern. These samples had the most average peak numbers, the highest peak intensities, and the best capturing ability of low abundance proteins or peptides [23]. Besides low degree of automation, time-consuming and poor repeatability, traditional 2-DE had an ineffective detection of proteins with low-abundance, hydrophobicity, extreme alkalinity, extreme acidity, very high molecular weight $(>200 \mathrm{kD}$ ) or very small molecular weight $(<10 \mathrm{kD})$. The reproducibility of mass-spectral peaks abtained by protein chip-SELDI-TOF-MS in different research groups was very low. Target protein bound to the chip is difficult to elute for further identification. Labelfree quantification strategies using high-resolution mass spectrometers do not require isotope label as internal standards and are economic as well as high-throughput. However, label-free quantitative proteomic techniques is still not mature enough and has great dependence on the reproducibility of the MS Experiment. Compared with isotope-labeling methods, label-free experiments need to be more carefully controlled due to possible error caused by run-to-run variations in performance of LC and MS [24]. The cDNA Microarray is applied to find disease-related markers from mRNA levels, whereas protein is the practitioner of human life activities. Protein with abnormal regulation and modification are always involved in malignant processes of AML with normal chromosomes and genes. 2) Serum specimens were as our study object, excluding the impact of fibrinogen and anticoagulant. Unlike some previous report, sera were pre-treated with urea and CHAPS. We used non-denatured serum samples. 3) We observed the peptides ranging from 700 to $10000 \mathrm{Da}$. Peptides as potential biological information molecules were quite abundant in serum. Comparing with proteins, peptides have the advantages of small MW, easy-transformed
A

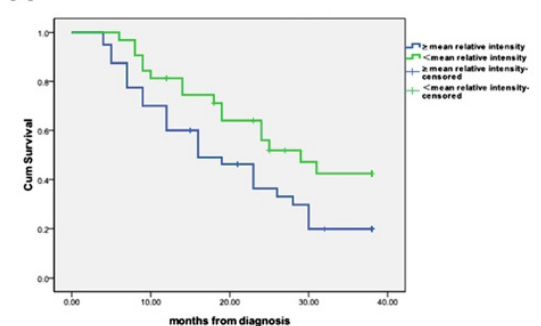

B

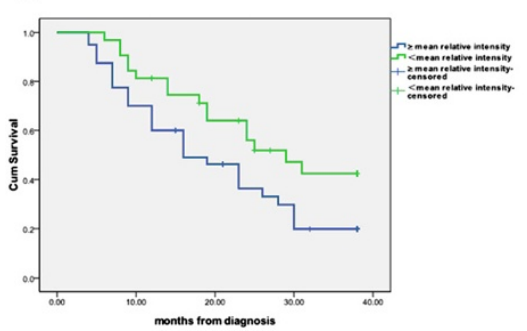

C

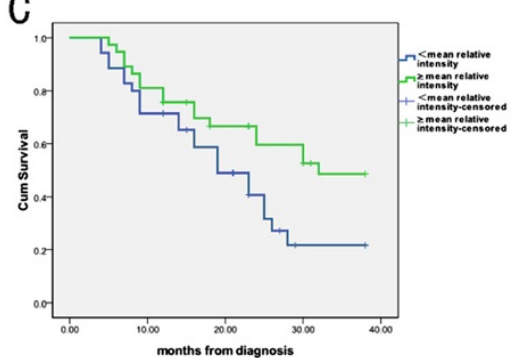

Figure 8 Correlation between relative intensity of three peptides and overall survival (OS). (A) Patients who had higher relative intensity of ubiquitin-like modifier activating enzyme 1 ( $\geq$ mean relative intensity) had a significantly inferior outcome. (B) The OS rate was higher in patients with increased relative intensity ( $\geq$ mean relative intensity) of isoform 1 of fibrinogen alpha chain precursor. (C) Lower relative intensity of platelet factor $4(<$ mean relative intensity) associated with an unfavorable OS. 
structure and easier chemical synthesis. Leukemogenesis is a complex process in which lots of peptides are involved. It needs high throughput proteomics technology to identify theses peptides. The structure of these peptides, their function and role in the pathological process of disease are expected to be further clarified so as to better defining disease pathogenesis and guiding clinical practice.

The relative intensity differences of the peptides in the QC diagnostic model were further compared in the AML different groups and the healthy control group. We found that the peptide with elevated relative intensity in newly diagnosed group was reduced after complete remission, when relapsed, its relative intensity again increased; the peptides which were downregulated in the newly diagnosed group were upregulated after complete remission and down-regulated when relapsed. Kaplan-Meier analyses of OS show a significantly inferior outcome for patients with higher relative intensity of ubiquitin-like modifier activating enzyme 1 peptide fragment compared with the patients with lower relative intensity. The other two peptides with lower relative intensities were negatively correlated with patients' overall survival. All these data suggest that these peptides can be used as potential predictive markers of treatment response, disease relapse, monitoring minimal residual disease and clinical outcome assessment.

Ubiquitin-like modifier activating enzyme 1 is also known as Ubiquitin-activating enzyme E1. Ubiquitinproteasome pathway, an important protein quality control system in eukaryotic cells, is the major route by which cells rid themselves of excess proteins, such as damaged or unwanted intracellular proteins to regulate cell proliferation and differentiation, cell cycle progression, cell signal transduction, ultimately to maintain the cell normal function. Ubiquitination is a multistep enzymatic cascade in which ubiquitin is conjugated to target proteins with the assistance of E1 (Ubiquitinactivating enzyme), E2 (Ubiquitin-conjungating enzyme) and E3 (Ubiquitin ligase), then recognized, unfolded, and degraded by the proteasome enzyme complex $[25,26]$.

The ubiquitin pathway has been implicated in several forms of malignancy through the degradation of tumor suppressor proteins [26]. In uterine cervical carcinomas, the tumor-suppressor protein p53 is tagged by the human papilloma virus (HPV) oncoprotein E6 for ubiquitin-mediated degradation resulting in transformed cells [27]. By immunoblotting, Xu's group found the levels of ubiquitinated proteins were significantly increased in leukemia cell line K562, U937, NB4, THP1 and leukemia cells from 12 de novo AML patients compared with normal hematopoietic cells. But the levels of E1 protein in malignant cells did not differ from that in normal cells. Thus, these results suggest that the increased activity of pathway is not due to a greater abundance of the E1 enzyme, while E1 enzyme is more actively used in malignant cells. Inhibition of E1 enzyme activity of the four leukemia cell lines by RNA interference and chemical inhibitors PYZD-4409 can induce cell death, and an increase in p53 content, the same result was seen in multiple myeloma LP1 cell lines and the My-5 cells. Finally, in a mouse model of leukemia established by hMDAY-D2, Intraperitoneal administration of PYZD-4409 decreased tumor weight and volume compared with control without untoward toxicity [28]. We found that the relative intensity of serum ubiquitinlike modifier activating enzyme 1 peptide was elevated in newly diagnosed AML patients compared with healthy controls. But UBA1 protein levels in leukemia cells and normal cells are not different by immunoblotting. Maybe some growth negative regulator proteins of AML have an increased ubiquitination due to increased E1 enzyme activity but not a greater abundance of the E1 enzyme. These proteins are further degraded leading to leukemogenesis. The relative intensity of this peptide was declined in the AML patients in CR after chemotherapy and negatively regulate proteins might have a reduced degradation, but its relative intensity was increased again when AML relapsed, suggesting that the peptide may play a role in the pathogenesis of AML. It can be potential indicators for predicting AML treatment response and monitoring MRD. Its function and biological activity need further studies.

Fibrinogen is a glycoprotein composed of three pairs of unequal polypeptide chain. Fibrinogen alpha chain is just one of the three chains present in the circulating fibrinogen molecule (the other two being beta and gamma). A number of studies has shown that there are an increased expression of fibrinogen in many malignant tumors, such as pancreatic cancer, renal cell carcinoma, endometrial carcinoma, osteosarcoma, esophageal squamous cell carcinoma and so on [29]. Preston's group considered that fibrinogen as an acute phase protein in pancreatic cancer had increased expression, because the result of increased synthesis of fibrinogen was associated with an ongoing inflammatory response to tumor [30]. Some studies suggest that tumor cells could promote coagulation process by interacting with endothelial cells and platelets, then by releasing active biological substances that activate platelets, which leads to high level of fibrinogen in the cancer patients' blood. It is further indicated that fibrinogen could be an independent prognostic factor for disease-free, distant-free and overall survival in endometrial cancer, esophageal cancer and renal cell carcinoma [31-34]. The relative intensity of isoform 1 of fibrinogen alpha chain precursor peptide fragment was decreased in newly diagnosed AML and 
increased to normal level when patients received complete remission. When AML patients relapsed, the relative intensity was reduced again. The results have been validated by western blot analysis. We found fibrinogen $\alpha$ chain was highly expressed in newly diagnosed AML serum by ELISA (Data isn't shown). It appears that a large part of the human serum peptidome as detected by MALDI-TOF MS is produced ex vivo by degradation of endogenous substrates by endogenous proteases. Peptides are generated during the proteolytic cascades that occur in the intrinsic pathway of coagulation and complement activation. Some of these are known bioactive molecules, others represent cleaved propeptides, and still others are seemingly random internal fragments of the precursor proteins. However, the observed cleavage sites are generally consistent with trypsin- and chymotrypsin-like activities of known serine proteases (kallikreins, plasmin, thrombin, factor I, etc.) [17]. The peptide identified (G592-V629) could be a putative plasmin- generated proteolytic fragments. In the light of this evidence, a down-regulation of the identified peptide (4089.7 Da) could be due to a hypothetical reduced enzymatic activity able to attack the Cterminal end of fibrinogen alpha chain.

PF4 is ELR (-) CXC chemokines, synthesized by megakaryocyte, stored in platelet alpha particles. Shi's group used WCX2-Proteinchip arrays and SELDI-TOF-MS, HPLC-LC-MS/MS found that pediatric ALL patients had a reduced PF4 expression [35]. Kim's group found that PF4 protein levels were a good indicator for the recovery of blood count in the complete remission of acute myeloid leukemia [36]. Our study showed that compared with healthy control group, the relative intensity of PF4 was reduced in newly diagnosed AML group. The relative intensity was elevated to normal level after AML patients achieved CR. When AML refractory \& relapsed, the relative intensity was decreased again. By immunoblotting, PF4 protein was significantly decreased in newly diagnosed and refractory \& relapsed AML cells. These findings are consistent with Kim's. As PF4 is secreted by platelets and hematologic malignancies always have reduced platelets. In order to determine whether the reduced serum PF4 expression was associated with reduced platelet in MDS patients and benzene-exposed workers, studies revealed that lower PF4 expression was not due to thrombocytopenia $[37,38]$. We determined and compared serum PF4 content between newly diagnosed AML with and without thrombocytopenia. We found no difference between the two groups. Linear regression analysis showed that no correlation between PF4 content and platelet count.

\section{Conclusions}

In conclusion, AML QC model had high sensitivity and specificity to discriminate AML patients from healthy controls by application of ClinProt system with high throughput and good repeatability. Ubiquitin-like modifier activating enzyme 1 peptide fragment, which is up-regulated in newly diagnosed AML patients, may decrease and approach to the normal level in their relative intensities after complete remission. When AML refractory \& relapsed, the relative intensity is elevated again. Results are contrary to isoform 1 of fibrinogen alpha of chain precursor peptide fragment and PF4. KaplanMeier analyses of overall survival show that relative intensity of peptides is correlated with patient's clinical outcome. We speculate these peptides can be used as potential markers for predicting AML relapse, monitoring minimal residual disease and assessing clinical outcome.

\section{Methods}

\section{Patients' clinical data and serum samples}

This study was approved by the institutional Ethics Committee of the Hospital. 72 adult AML patients were randomly selected from those whose diagnosis was confirmed by myelocytic cytological diagnosis in the Second Affiliated Hospital of Xi'an Jiao Tong University during a given period of time (2009.1-2012.1). The diagnosis to adult AML was conducted based on the FrenchAmerican-British (FAB) classification system. At the same time, 72 healthy controls were selected from adult healthy examinees without any diseases. In addition, 37 serum samples were obtained from AML patients with hematologic CR and 30 serum samples from refractory \& relapsed AML patients. A day 15 bone marrow puncture were performed. The diagnostic standards of hematologic CR were: bone marrow blasts $<5 \%$; absence of blasts with Auer rods; absence of extramedullary disease; absolute neutrophil count $>1.0 \times 10^{9} / \mathrm{L}$, platelet counts $>100 \times 10^{9} / \mathrm{L}$, independence of red cell transfusions. Resistant disease (RD) was defined as failure to achieve CR or CR with incomplete blood recovery (CRi ) (general practice; phase $2 / 3$ trials), or failure to achieve $\mathrm{CR}, \mathrm{CRi}$, or partial remission(PR) (phase 1 trials); only includes patients surviving 7 days following completion of initial treatment, with evidence of persistent leukemia by blood and/or bone marrow examination. Relapse was defined as bone marrow blasts $>5 \%$; or reappearance of blasts in the blood; or development of extramedullary disease. All patients and healthy examinees signed informed consents.

Clinical characteristics of newly diagnosed AML patients, patients with AML-CR and AML-RD are shown in Table 5. The serum samples were collected according to standard protocol. Fasting blood samples were collected from patients in the morning and allowed to clot at room temperature for $2 \mathrm{~h}$. Sera were then separated by centrifugation at $2500 \mathrm{rpm}$ for $10 \mathrm{~min}$ and stored at $-80^{\circ} \mathrm{C}$ until analysis. The length of cryo-preservation 
Table 5 Clinical features of patients in different AML groups before chemotherapy

\begin{tabular}{|c|c|c|c|c|c|c|c|}
\hline \multirow[t]{2}{*}{ Clinical features } & & \multicolumn{6}{|c|}{ AML } \\
\hline & & \multicolumn{2}{|c|}{ Newly diagnosed } & \multicolumn{2}{|c|}{ CR } & \multicolumn{2}{|c|}{ Refractory \& relapsed } \\
\hline \multirow[t]{2}{*}{ Sex } & male & \multicolumn{2}{|c|}{38} & \multicolumn{2}{|c|}{19} & \multicolumn{2}{|c|}{13} \\
\hline & female & \multicolumn{2}{|c|}{34} & \multicolumn{2}{|c|}{18} & \multicolumn{2}{|c|}{17} \\
\hline Age(year) & & \multicolumn{2}{|c|}{$46(18-79)$} & \multicolumn{2}{|c|}{$48(18-69)$} & \multicolumn{2}{|c|}{$47(19-77)$} \\
\hline $\mathrm{WBC}\left(\times 10^{9} / \mathrm{L}\right)$ & & \multicolumn{2}{|c|}{$23.5(0.25-143)$} & \multicolumn{2}{|c|}{$11.83(2.96-101.69)$} & \multicolumn{2}{|c|}{$23.58(0.94-123.6)$} \\
\hline $\mathrm{Hb}(\mathrm{g} / \mathrm{L})$ & & \multicolumn{2}{|c|}{$73(28-128)$} & \multicolumn{2}{|c|}{ 111.5(69-135) } & \multicolumn{2}{|c|}{$69(55-152)$} \\
\hline $\operatorname{PLT}\left(\times 10^{9} / L\right)$ & & \multicolumn{2}{|c|}{$26(12-287)$} & \multicolumn{2}{|c|}{$74(48-174)$} & \multicolumn{2}{|c|}{$31(9-172)$} \\
\hline \multirow[t]{8}{*}{ Subtype } & & Mo & 0 & Mo & 0 & MO & 0 \\
\hline & & M1 & 6 & M1 & 2 & M1 & 3 \\
\hline & & M2 & 8 & M2 & 5 & M2 & 2 \\
\hline & & M3 & 6 & M3 & 5 & M3 & 0 \\
\hline & & M4 & 24 & M4 & 11 & M4 & 13 \\
\hline & & M5 & 28 & M5 & 14 & M5 & 12 \\
\hline & & M6 & 0 & M6 & 0 & M6 & 0 \\
\hline & & M7 & 0 & M7 & 0 & M7 & 0 \\
\hline \multirow[t]{6}{*}{ Chromosome Abnormality } & & $t(15 ; 17)$ & 6 & $t(15 ; 17)$ & 5 & $t(8 ; 21)$ & 1 \\
\hline & & $\mathrm{t}(8 ; 21)$ & 4 & $\mathrm{t}(8 ; 21)$ & 2 & $t(3 ; 12)$ & 2 \\
\hline & & $t(3 ; 12)$ & 2 & $11 q 23$ & 2 & $11 q 23$ & 4 \\
\hline & & $11 q 23$ & 6 & & & +8 & 3 \\
\hline & & +8 & 4 & & & -7 & 2 \\
\hline & & -7 & 2 & & & & \\
\hline \multirow[t]{6}{*}{ Molecular Genetics Abnormality } & & PML-RARa & 6 & PML-RARa & 5 & AML-ETO & 1 \\
\hline & & AML-ETO & 4 & AML-ETO & 2 & MLL & 3 \\
\hline & & MLL & 6 & & & FLT3-ITD & 5 \\
\hline & & FLT3-ITD & 6 & & & C-kit Mut & 2 \\
\hline & & C-kit & 3 & & & NPM1 Mut & 3 \\
\hline & & NPM1 Mut & 3 & & & & \\
\hline Sternal tenderness & & $57 / 72$ & & $25 / 37$ & & $26 / 30$ & \\
\hline Lymphadenectasis & & $39 / 72$ & & $14 / 37$ & & $21 / 30$ & \\
\hline Splenohepatomegalia & & $36 / 72$ & & $16 / 37$ & & $14 / 30$ & \\
\hline Curative effect & & $32 / 72$ & & $37 / 37$ & & $17 / 30$ & \\
\hline
\end{tabular}

This table showed clinical features of AML patients in different groups at the time of diagnosis. MLL refers to MLL rearrangement. Mut is the abbreviation of mutation. Curative effect refers to achieved complete remission after 2 courses of standard chemotherapy.

period for all serum samples were less than 6 months [39]. For the reproducibility experiments, serum from each AML patient and each healthy control used the same MALDI-TOF-MS instrument to run three withinrun assays and three between-run assays.

\section{Weak cation exchange magnetic beads based serum peptides purification}

Weak cation exchange magnetic beads kit was purchased from Bruker Daltonics Inc. (Billerica, MA - USA). All purifications were performed in a one-step procedure according to manufacturers' instructions through a standard protocol (ClinProtTM, Bruker Daltonics).
1) $5 \mu \mathrm{l}$ serum samples, $10 \mu \mathrm{l}$ Binding Buffer and $10 \mu \mathrm{l} \mathrm{MB}-\mathrm{WCX}$ were mixed by pipetting in a $200 \mu \mathrm{L}$ Orcugen sample tube. 2) After 5 minutes standing, the tube was placed in a magnetic bead separator for $1 \mathrm{~min}$. Then the supernatant was discarded carefully with a pipette. 3) Subsequently $100 \mu \mathrm{l}$ Washing Buffer was added, the tube was moved to and fro in two adjacent holes of the magnet separator, and then placed in the magnet separator for $1 \mathrm{~min}$ so as to make magnetic beads adhere to the wall of the tube. Afterwards, the supernatant was discarded carefully using a pipette. 4) Washing process was repeated twice. After binding and washing, $5 \mu$ Elution Buffer was added to the tube to elute the 
bound peptides from the magnetic beads, and then the tube was placed in the magnet separator for $2 \mathrm{~min}$. After that, the supernatant was transferred into a $0.5 \mathrm{ml}$ tube with $5 \mu \mathrm{l}$ Stabilization Buffer. Binding, Washing, Elution, and Stabilization Buffer were all provided by Bruker Daltonics Inc. 5) Matrix preparation: matrix solution with $\alpha$-Cyano-4- hydroxycinnamic acid (HCCA) of $0.3 \mathrm{~g} / \mathrm{l}$ in ethanol: acetone 2:1 (prepared freshly every day).

\section{Data acquisition by MALDI-TOF mass spectrometry}

1) At first, $1 \mu \mathrm{L}$ eluted sample was spotted onto a MALDI-TOF AnchorChip (TM) target $(600 \mu \mathrm{m}$ anchor diameter), and air-dried at room temperature, then $1 \mu \mathrm{L}$ matrix $(0.3 \mathrm{mg} / \mathrm{ml} \mathrm{HCCA}, 50 \%$ ACN, $2 \%$ TFA) was spotted onto MALDI-TOF AnchorChip. 2) Anchorchip target plate was placed into the Micro flex mass spectrometer (Bruker Daltonics). 3) After calibration of instrument by cilnplot standard, samples were detected, scan range was $0.7-10 \mathrm{KD}$. FlexControl2.2 software was applied to acquire data and peptide profiling was constituted by different mass to charge ratio.

\section{Data processing and statistical analysis}

Original mass spectrums were normalized by Flexanalysis 3.0 software, including soomthing and substrate baseline. Where after, we selected statistical algorithm built-in Clinprotools2.2 software for statistical analysis and acquization of differently expressed peptides. ANOVA test or Wilcoxon rank sum test was used to analyse peptide peak intensity differences in each group. Statistically significant was defined as $\mathrm{p}<0.05$. GA, SNN and QC were applied to establish model to distinguish AML and healthy control. The patients were categorized into two groups according to the relative intensities of peptides $(\geq$ mean versus $<$ mean). Overall Survival was estimated by the Kaplan-Meier method and compared using a log-rank test. The event was defined as the time from initial diagnosis to treatment-related death time.

\section{Identification of peptide biomarkers}

We utilized a nano-liquid chromatography-electro spray ionization-tandem mass spectrometry (nano-LC/ESImass spectrometry/mass spectrometry) system consisting of an Aquity UPLC system (Waters Corporation, Milford, USA) and a LTQ Obitrap XL mass spectrometer (Thermo Fisher, waltham, MA,USA) equipped with a nano-ESI source(Michrom Bioresources, Auburn, USA) to perform peptide sequencing and peptide identification. The peptide solutions purified by magnetic beads, were loaded to a C18 trap column (nanoACQUITY) $(180 \mu \mathrm{m} \times$ $20 \mathrm{~mm} \times 5 \mu \mathrm{m}$ (symmetry)). The flow rate was $15 \mu \mathrm{l} / \mathrm{min}$. Then the desalted peptides were analyzed by $\mathrm{C} 18$ analytical column (nano ACQUITY) $(75 \mu \mathrm{m} \times 150 \mathrm{~mm} \times 3.5 \mu \mathrm{m}$ (symmetry)) at a flow rate of $400 \mathrm{nl} / \mathrm{min}$ for $60 \mathrm{~min}$. The mobile phases A (5\% acetonitrile, $0.1 \%$ formic acid) and B ( $95 \%$ acetonitrile, $0.1 \%$ formic acid) were used for analytical columns. The gradient elution profile was as follows: $5 \% \mathrm{~B}-45 \% \mathrm{~B}-80 \% \mathrm{~B}-80 \% \mathrm{~B}-5 \% \mathrm{~B}-5 \% \mathrm{~B}$ in $60 \mathrm{~min}$. The spray voltage was $1.8 \mathrm{kV}$. MS scan time was $60 \mathrm{~min}$. Experimental mode were Data Dependent and Dynamic Exclusion, scilicet a second cascade of the parent ion within 10 seconds added to the exclusion list for 90 seconds. Mass scan range was from $\mathrm{m} / \mathrm{z} 400$ to 2000 . MS scan used Obitrap, resolution was set at 100000 . CID and MS/MS scan applied LTQ. In MS spectrogram, we selected single isotope composed of 10 ions with strongest intensity as parent ion for MS/MS (Single charge being excluded, not as parent ion). We applied data analysis software Bioworks Browser 3.3.1 SP1 for Sequest ${ }^{\mathrm{Th}}$ retrieving. Retrieval Database was International Protein Index (IPI human v3.45 fasta with 71983 entries). Parent ion error was set at $100 \mathrm{ppm}$, fragment ions error at $1 \mathrm{Da}$, digested mode at non-digested and variable modifications at methionine oxidation.

\section{Determination of serum PF4 by ELISA}

We used ELISA to assay serum PF4 content in 40 newly diagnosed AML patients and 40 healthy controls and compared the differences between the two groups. Detailed procedure was according to manufacturers' instructions of ELISA kit (R\&D, USA). Furthermore, we analyzed the correlation of platelet counts and serum PF4 content in AML patients. Independent sample t-test comparative analysis was done through the statistical software SPSS 17.0. Correlation analysis used linear regression analysis. Statistically significant was defined as $\mathrm{p}<0.05$.

\section{Western blot analysis for validation}

Sodium dodecyl sulfate polyacrylamide gel electrophoresis (SDS-PAGE) and immunoblotting were performed essentially as described elsewhere. Briefly, cell pellets were resuspended on ice in lysis buffer containing $10 \mathrm{mM}$ Tris- $\mathrm{HCl}$ (pH 7.4), $5 \mathrm{mM} \mathrm{MgCl} 2,1 \%$ Triton $\mathrm{X}-100,100 \mathrm{mM} \mathrm{NaCl}, 10 \mathrm{mM} \mathrm{NaF}, 1 \mathrm{mM} \mathrm{Na} 3 \mathrm{VO} 4$ and a protease inhibitor cocktail. After sonication, cellular proteins were separated on an SDS-polyacrylamide gel and transferred to polyvinylidene fluoride membranes (Roche Diagnostics Corporation, Indianapolis, Indiana United States), which were probed with the appropriate primary antibodies. Immunoreactivity was detected with the relevant horseradish peroxidase-labeled secondary anti-bodies which, in turn, were visualized on an Image Reader Tano-5500 (Tano, Shanghai, China) using chemiluminescence substrate reagent purchased from 7 sea pharmtech (Shanghai, China) For quantification of the data, the images were further analyzed on the same instrument using 2D Densitometry Image Analyzer IPP 7.0 software (Tano, Shanghai, China). 


\section{Additional file}

Additional file 1: Figure S1. Serum peptide fingerprints of the same serum through same processing in three-repeated experiments. (A) Serum peptide fingerprints of the same acute leukemia through same processing in three-repeated experiments. (B) Serum peptide fingerprints of the same healthy control through same processing in three-repeated experiments.

\section{Abbreviations}

MRD: Minimal residual disease; MB-WCX: Weak cation exchange magnetic beads; MALDI-TOF-MS: Matrix assisted laser desorption ionization time of flight mass spectrometry; AML: Acute myeloid leukemia; HPLC-MS/MS: High-performance liquid chromatography tandem mass spectrometry/mass spectrometry; CR: Complete remission; QC: Quick classifier; UBA1: Ubiquitinlike modifier activating enzyme 1; PF4: Platelet factor 4; RTQ-PCR: Real-time quantitative polymerase chain reaction; SELDI-TOF-MS: Surface enhanced laser desorption ionization time of flight mass spectrometry; 2-DE: Two-dimensional gel electrophoresis, Rho-GDP; MM: Multiple myeloma; SNN: Supervised neural network; CV: Coefficient of variation; MW: Molecular weight; GA: Genetic algorithm; ELISA: Enzyme linked immunosorbent assay; OS: Overall survival; HPV: Human papilloma virus.

\section{Competing interests}

The authors declare no conflict of interests with any company or financial organization.

\section{Authors' contributions}

$J B$ and $Y Z$ were involved in serum peptide purification, writing the draft of the manuscript; JY performed serum peptide profiling data acquisition and processing; $Y Y$ and JLW were involved in serum samples and clinical data collection; ALH, WGZ and CH designed the experiments and supervised the research manuscript. All authors read and approved the manuscript

\section{Acknowledgements}

This work was supported by Program for Changjiang Scholars and Innovative Research Team in University (PCSIRT:1171).

\section{Author details}

'Department of Hematology, Second Affiliated Hospital, Medical School of Xi'an Jiaotong University, 157 Xiwu Road, Xincheng District, Xi'an, Shaanxi 710004, PR China. ${ }^{2}$ Department of Genetics and Molecular Biology, Medical school of Xi'an Jiaotong University/Key Laboratory of Environment and Disease-Related Gene, Ministry of Education, 76 Western Yanta Road, Xi'an, Shaanxi 710061, PR China.

Received: 20 March 2013 Accepted: 1 August 2013 Published: 3 August 2013

\section{References}

1. Marcucci G, Haferlach T, Döhner H: Molecular genetics of adult acute myeloid leukemia: prognostic and therapeutic implications. J Clin Oncol 2011, 29:475-486.

2. Sanz MA, Lo-Coco F: Modern approaches to treating acute promyelocytic leukemia. J Clin Oncol 2011, 29:495-503.

3. Smith M, Barnett M, Bassan R, Gatta G, Tondini C, Kern W: Adult acute myeloid leukaemia. Critic rev oncol/hematol 2004, 50:197-222.

4. Buccisano F, Maurillo L, Del Principe MI, Del Poeta G, Sconocchia G, Lo-Coco $F$, et al: Prognostic and therapeutic implications of minimal residual disease detection in acute myeloid leukemia. Blood 2012, 119:332-341.

5. Martorella A, Robbins R: Serum peptide profiling: identifying novel cancer biomarkers for early disease detection. Acta Biomed 2007, 78:123-128.

6. Albitar M, Potts SJ, Giles FJ, O'Brien S, Keating M, Thomas D, et al: Proteomic-based prediction of clinical behavior in adult acute lymphoblastic leukemia. Cancer 2006, 106:1587-1594.

7. Zou L, Wu Y, Pei L, Zhong D, Gen M, Zhao T, et al: Identification of leukemia-associated antigens in chronic myeloid leukemia by proteomic analysis. Leukemia research 2005, 29:1387-1391.
8. Mohamedali A, Guinn B, Sahu S, Thomas N, Mufti GJ: Serum profiling reveals distinctive proteomic markers in chronic myeloid leukaemia patients. British J haematol 2009, 144:263-265.

9. Cui J, Li W, Wang J, Li A, Li H, Wang H, et al: Proteomics-based identification of human acute leukemia antigens that induce humoral immune response. Mol Cell Proteomics 2005, 4:1718-1724.

10. Cheng AJ, Chen LC, Chien KY, Chen YJ, Chang JTC, Wang HM, et al: Oral cancer plasma tumor marker identified with bead-based affinity-fractionated proteomic technology. Clin Chem 2005, 51:2236-2244.

11. Villanueva J, Philip J, Entenberg D, Chaparro CA, Tanwar MK, Holland EC, et al: Serum peptide profiling by magnetic particle-assisted, automated sample processing and MALDI-TOF mass spectrometry. Analytical chemistry 2004, 76:1560-1570.

12. Sogawa $K$, Satoh M, Kodera $Y$, Tomonaga $T$, lyo M, Nomura F: A search for novel markers of alcohol abuse using magnetic beads and MALDI-TOF /TOF mass spectrometry. PROTEOMICS-Clinic Appl 2009, 3:821-828.

13. Ketterlinus R, Hsieh SY, Teng SH, Lee H, Pusch W: Fishing for biomarkers: analyzing mass spectrometry data with the new ClinProTools software. Biotechniques 2005, 38:37-40.

14. Leung SM, Dikler S, Samuel CM: A new approach for profiling ovarian cancer serum using functionalizied magnetic beads, anchorchip technology, MALDITOF MS, MALDI-TOF/TOF MS, and bioinformatics. San Francisco, CA, United States: Presented at the Sixth International Symposium on Mass Spectrometry in the Health and Life Science; 2003.

15. Mian S, Ugurel S, Parkinson E, Schlenzka I, Dryden I, Lancashire L, et al: Serum proteomic fingerprinting discriminates between clinical stages and predicts disease progression in melanoma patients. $J$ Clin Oncol 2005, 23:5088-5093.

16. de Noo ME, Mertens BJA, Özalp A, Bladergroen MR, van der Werff MPJ, van de Velde $\mathrm{CJ}$, et al: Detection of colorectal cancer using MALDI-TOF serum protein profiling. Eur J Cancer 2006, 42:1068-1076.

17. Villanueva J, Shaffer DR, Philip J, Chaparro CA, Erdjument-Bromage H, Olshen $A B$, et al: Differential exoprotease activities confer tumor-specific serum peptidome patterns. J Clin Investig 2006, 116:271-284.

18. Freed GL, Cazares LH, Fichandler CE, Fuller TW, Sawyer CA, Stack BC, et al: Differential capture of serum proteins for expression profiling and biomarker discovery in Pre-and post treatment head and neck cancer samples. Laryngoscope 2009, 118:61-68.

19. He A, Bai J, Huang C, Yang J, Zhang W, Wang J, et al: Detection of serum tumor markers in multiple myeloma using the CLINPROT system. Int J hematol 2012, 95:1-7.

20. Baumann S, Ceglarek U, Fiedler GM, Lembcke J, Leichtle A, Thiery J: Standardized approach to proteome profiling of human serum based on magnetic bead separation and matrix-assisted laser desorption/ ionization time-of-flight mass spectrometry. Clinical chemistry 2005, 51:973-980.

21. Elssner T, Fahr K, Thomas I: Magnetic bead based human plasma profiling to discriminate acute lymphatic leukaemia from non-disease samples. ASMS 2004.

22. Liang T, Wang N, Li W, Li A, Wang J, Cui J, et al: Identification of complement C3f-desArg and its derivative for acute leukemia diagnosis and minimal residual disease assessment. Proteomics 2009, 10:90-98.

23. Qiu F, Liu H, Zhang X, Tian Y: Optimization of magnetic beads for MALDITOF MS analysis. Front Biosci 2009, 14:3712-3723.

24. Zhu W, Smith JW, Huang CM: Mass spectrometry-based label-free quantitative proteomics. BioMed Res Int 2010, 2010:840518. doi:10.1155/ 2010/840518.

25. Hershko A: The ubiquitin system for protein degradation and some of its roles in the control of the cell division cycle\&ast. Cell Death \& Differentiation 2005, 12:1191-1197.

26. Burger AM, Seth AK: The ubiquitin-mediated protein degradation pathway in cancer: therapeutic implications. Eur J Cancer 2004, 40:2217-2229.

27. Scheffner M, Huibregtse JM, Howley PM: Identification of a human ubiquitin-conjugating enzyme that mediates the E6-AP-dependent ubiquitination of p53. Proc Natl Acad Sci U S A 1994, 91:8797-8801.

28. Xu GW, Ali M, Wood TE, Wong D, Maclean N, Wang $X$, et al: The ubiquitin-activating enzyme E1 as a therapeutic target for the treatment of leukemia and multiple myeloma. Blood 2010, 115:2251-2259. 
29. Tao YL, Li Y, Gao J, Liu ZG, Tu ZW, Li G, et al: Identifying FGA peptides as nasopharyngeal carcinoma-associated biomarkers by magnetic beads. J cellul biochem 2012, 113:2268-2278.

30. Preston T, Slater C, McMillan DC, Falconer JS, Shenkin A, Fearon KCH: Fibrinogen synthesis is elevated in fasting cancer patients with an acute phase response. I nutrit 1998, 128:1355-1360.

31. Palumbo JS, Kombrinck KW, Drew AF, Grimes TS, Kiser JH, Degen JL, et al: Fibrinogen is an important determinant of the metastatic potential of circulating tumor cells. Blood 2000, 96:3302-3309.

32. Palumbo JS, Potter JM, Kaplan LS, Talmage K, Jackson DG, Degen JL: Spontaneous hematogenous and lymphatic metastasis, but not primary tumor growth or angiogenesis, is diminished in fibrinogen-deficient mice. Cancer research 2002, 62:6966-6972.

33. Verheul HMW, van Erp K, Homs MY, Yoon G, van Der Groep P, Rogers C, et al: The relationship of vascular endothelial growth factor and coagulation factor (fibrin and fibrinogen) expression in clear cell renal cell carcinoma. Urology 2010, 75:608-614.

34. Takeuchi H, Ikeuchi S, Kitagawa Y, Shimada A, Oishi T, Isobe Y, et al: Pre-treatment plasma fibrinogen level correlates with tumor progression and metastasis in patients with squamous cell carcinoma of the esophagus. J gastroenterol hepatol 2007, 22:2222-2227.

35. Shi L, Zhang J, Wu P, Feng K, Li J, Xie Z, et al: Discovery and identification of potential biomarkers of pediatric acute Lymphoblastic Leukemia. Proc Natl Acad Sci USA 2009, 7:7. doi:10.1186/1477-5956-7-7.

36. Kim JY, Song HJ, Lim HJ, Shin MG, Kim JS, Kim HJ, et al: Platelet factor-4 is an indicator of blood count recovery in acute myeloid leukemia patients in complete remission. Mol Cell Proteomics 2008, 7:431-441.

37. Aivado M, Spentzos D, Germing U, Alterovitz G, Meng XY, Grall F, et al: Serum proteome profiling detects myelodysplastic syndromes and identifies CXC chemokine ligands 4 and 7 as markers for advanced disease. Proc Natl Acad Sci U S A 2007, 104:1307-1312.

38. Vermeulen R, Lan Q, Zhang L, Gunn L, McCarthy D, Woodbury RL, et al: Decreased levels of CXC-chemokines in serum of benzene-exposed workers identified by array-based proteomics. Proc Natl Acad Sci USA 2005, 102:17041-17046.

39. Elssner T, Kostrzewa M: CLINPROT-a MALDI-TOF MS based system for biomarker discovery and analysis. Clinic Proteomics 2006, 8:167.

doi:10.1186/1477-5956-11-39

Cite this article as: Bai et al:: Potential biomarkers for adult acute myeloid leukemia minimal residual disease assessment searched by serum peptidome profiling. Proteome Science 2013 11:39.

\section{Submit your next manuscript to BioMed Central and take full advantage of:}

- Convenient online submission

- Thorough peer review

- No space constraints or color figure charges

- Immediate publication on acceptance

- Inclusion in PubMed, CAS, Scopus and Google Scholar

- Research which is freely available for redistribution

Submit your manuscript at www.biomedcentral.com/submit 